\title{
International academic staff in UK HE: Campus internationalisation and innovation in academic practice
}

Dr Sonal Minocha ${ }^{a}{ }^{1}$, Prof Chris Shiel ${ }^{a}$ and Dean Hristov ${ }^{a}$

${ }^{a}$ Bournemouth University, Bournemouth \& Poole, United Kingdom;

Author 1: Dr Sonal Minocha, Pro Vice-Chancellor (Global Engagement)

Bournemouth University

P508, Talbot Campus

Fern Barrow

Poole, UK

BH12 5BB

Author 2: Prof Chris Shiel, Professor, Faculty of Science and Technology

Bournemouth University

P508, Talbot Campus

Fern Barrow

Poole, UK

BH12 5BB

Author 3: Dr Dean Hristov, Global Talent Research Analyst

Bournemouth University

Talbot Campus

Fern Barrow

Poole

Dorset

BH12 5BB

${ }^{1}$ Corresponding Author. Email: sonalminocha@yahoo.com 


\title{
International academic staff in UK HE: Campus internationalisation and innovation in academic practice
}

\begin{abstract}
Amidst opportunities for universities to consider international academic staff in supporting internationalisation and innovation in academic practice, there is very little research to provide insights into their attitudes towards institutional approaches and frameworks in place to enable this. This paper focuses on this research gap, suggesting that this academic community might enhance the development of internationally-informed and innovative pedagogic practice. The research reported within the paper constitutes a preliminary study, set within a UK Higher Education (HE) case study setting. Methods included focus groups and themed in-depth interviews with a sample of 34 international academic staff from over 15 countries. The findings and discussion provide insights into the perspectives and experiences of international academic staff in relation to the Postgraduate Certificate in Teaching and Learning and other institutional practice. Innovative pedagogic practice as enabled by international academic staff is discussed, as are approaches to the internationalisation of the curricula. The findings are relevant to the UK H.E. context but also for the global context: academic institutions need to consider whether curriculum and processes are limited and limiting in favour of a narrow cultural lens.
\end{abstract}

\section{Keywords}

International staff, Internationalisation, Curriculum, Innovation, Diversity

\section{Introduction}

Internationalisation is high on the agenda for universities in the UK and beyond. An 'internationalised curriculum' and 'internationalisation at home' (Altbach, 2017; Jones and Brown 2007) have become important elements of universities international strategies, with institutions increasingly focused on developing and extending opportunities for home students to internationalise (Harrison, 2015; HEA, 2014a). However, whilst internationalisation has undoubtedly moved to the very core of institutional vision and mission over the last twenty years, the increasing commercialisation of this poses a threat, with the potential to devalue the concept and deteriorate its content (Brandenburg and De Wit, 2015).

Within this context, Brandenburg and de Wit, (2015) suggest that there is a need to rethink and redefine internationalisation and to move beyond a predominantly import-export model. Comprehensive internationalisation (Hudzik, 2015) requires a shift in institutional policy and practice.

Institutional attempts to achieve a broader perspective and better internationalisation practice, within the UK and internationally, have aspired to achieving internationalised campuses and an international student experience for all students. A range of approaches have been 
deployed, including: the use of international texts and international research examples in the classroom (Crose, 2011); overseas guest lectures (Pimpa, 2009); internationalisation of pedagogic practice (Robson and Turner, 2007); recruitment of international students and staff (Altbach and Knight, 2007); international staff as a source in international branch campuses (Cai and Hall, 2016) and initiatives to integrate home and international students (Harrison, 2015).

A large body of research has explored internationalisation from international students' perspectives (Warwick 2008; Caroll and Ryan 2005); a number of studies have also evaluated the positive and negative impacts of attempts to internationalise from home students' perspectives (Leask and Caroll 2011). There is also research that has sought students' views on being taught by 'foreigners' (Schutte and Winkvist-Noble 2006). Others have considered academics perspectives on teaching diverse groups (Barrington, 2004; Leask, 2009; Vita, 2001) with proposals developed of how to overcome the challenges. There is, however, little evidence of research that has sought to explore the perspectives of international academic staff, working outside of their national context.

Research on international academic staff in UK Higher Education Institutions (HEIs) has been largely focused on the first experiences of this academic community, when introduced to the UK HE context (Hsieh, 2012). However, this is often with little or no reference to discussions on how to actively involve them in internationalisation initiatives that utilise their own international experience and expertise fully (Willis and Hammond, 2014).

International academics are a rich source of cultural, pedagogic and academic experience. This is a theme that deserves further attention, but one that has not been high on the research radar (Clifford and Henderson, 2011), despite the ever increasing proportion of international staff in UK HE (Larner, 2015, Universities UK, 2017). Hsieh (2012) for example, contends that the range of opportunities to learn from the rich cultural and educational resources that the international academic community bring to the wider academic community, within UK HE, is under-explored. Similarly, Larner (2015) and Willis and Hammond (2014) argued that the role and functions of international staff in shaping a more global, context-driven and internationalised curriculum, is yet to be recognised by institutional leadership. Equally, the Higher Education Academy (HEA) calls for a stronger recognition of the diverse range of knowledge, experience, cultures, languages, beliefs, values, attitudes and meanings within the academic community, on the journey to internationalise campuses and classrooms (HEA, 2014b).

Against this backdrop, the overarching purpose of this paper is to explore international academic staff in UK HE as a resource of internationally-informed academic and pedagogic practice. In particular, this paper seeks to provide:

(i) an exploration of key dimensions of the UK HE context and related characteristics through the perspective of international academic staff;

(ii) a discussion of some perspectives and experiences of international academic staff in relation to the Postgraduate Certificate in Teaching and Learning (or equivalent), referred to in this paper as the PG Cert;

(iii) an exploration of pedagogic practice as practiced by international academic staff across borders, which may be considered as innovative; and

(iv) an exploration of some enablers of internationalised curriculum through the perspective of international academic staff. 
The remainder of this paper provides a brief summary of the literature on international academic staff in UK HE, which informed the research approach. The data is drawn from the authors' own HE institution. A qualitative analysis of findings is presented, before insights are offered for further research into the role of this academic cohort in the internationalisation of UK HE. The following section of this paper provides a review of the literature on international academic staff to set the scene for our investigation in situ.

\section{Literature review}

\section{Internationalisation at home}

Nearly two decades ago, Blight et al. (1999) argued that inward mobility programmes, which involve international student recruitment of international students are central to the internationalisation of HE institutions. In 2017, the concept of campus internationalisation (Wamboye et al., 2015) or 'internationalisation at home' (Jones and Brown 2007) is much broader and multi-dimensional than it used to be back in 1999. This progress in the concept has been achieved through embedding key campus internationalisation resources such as teaching and learning approaches for international students and classrooms (see Crose, 2011), internationalisation of pedagogic practice (see Robson and Turner, 2007), the establishment of international faculty (Jones, 2009) use of international case studies in the classroom (see Marschan-Piekkari and Welch, 2011), use of overseas guest lecturers (see Pimpa, 2009); internationalisation of pedagogic practice (see Robson and Turner, 2007), as well as the provision of international volunteering opportunities (see Jones 2008).

The recruitment of international students and staff (Altbach and Knight, 2007) and resultant efforts to integrate home and international students (Harrison, 2015) as a theme, has also gained prominence in the literature of campus internationalisation. There is, however, little evidence of research that has sought to explore the perspectives of international academic staff, working outside of their national context (Cai and Hall, 2016; Minocha, 2016).

Research to date on international academic staff in UK universities has been largely focused on the first experiences of this academic community, when introduced to the UK HE context (Hsieh, 2012). However, this is often with little or no reference to discussions on how to integrate them (Bailey et al., 2016) or actively involve them in internationalisation initiatives that utilise their own international experience and expertise fully (Willis and Hammond, 2014), or indeed seeing international academic staff as a resource of innovative pedagogic practice. The following section focuses specifically on key themes in the literature related to international academic staff.

\section{Key themes in the literature of international academic staff}

The experiences of international academic staff who have been recruited to work in an academic context, different to their national identity context constitutes the main body of research. For example, contributions address the challenges that international staff face in adapting to the UK HE context (Luxon and Peelo, 2009); the process of their acculturation into UK academic practice (Jiang et al., 2010; Maunder et al., 2009); the influence of linguistic capital on international academics performance and success (Sliwa and Johansson, 2015); barriers to mobility and migration of international staff (Mavroudi and Warren, 2013); 
the lack of understanding of international staff in UK HEIs (Hsieh, 2012); career accounts of the international academic community (Fernando and Cohen, 2015); international academic perspectives on careers in research-intensive UK universities (Khattab and Fenton, 2015) and, cultural and social adaptation of international staff into the UK HE context (Pherali, 2012, Walker, 2015).

Amidst a number of contributions into the introductory, environmental, social and cultural experiences of the international academic community in UK HE (see Hsieh, 2012; Jiang et al., 2010; Luxon and Peelo, 2009; Maunder et al., 2009), the ones related to experiences in the professional practice of this cohort appear to be prominent. Walker (2015) studied the lived experiences of newly-appointed international academics in UK HE, for example. She explored the professional practice of and how they fulfil their duties within a new academic environment often characterised with values, standards and norms with which they may not be familiar. Whilst international academic staff perceptions and experiences of the UK HE context have been widely researched, their accounts of UK HE policy and practice in more general terms, warrants further attention.

Fernando and Cohen (2015) explored the career accounts of Indian academic communities and how they utilise their resources and culturally-influenced thinking and actions in the UK HE context. Career trajectories of international academic staff in UK HE are however, often marked with a successful introduction to a new academic context - a process, which is often facilitated by the PG Cert or equivalent (see Kandlbinder and Peseta, 2009).

The PG Cert, whilst providing an introductory framework for international academic staff into UK HE, does not always accommodate nor it promotes internationalisation and innovation in the form of international curricular and pedagogic practice acquired internationally as concluded by Hristov and Minocha (2017). The experience of international academic staff in undertaking the PG Cert therefore also warrants further investigation.

The influence of language in the context of research-intensive institutions in relation to the international academic community has also been in the spotlight. Khattab and Fenton (2015), for instance, adopted a critical stance towards the increasing proportion of international staff in research-intensive universities in the UK. They debated the over-concentration of non-UK academics in research-only posts in elite institutions, and highlight a range of opportunities and challenges for institutions and international staff themselves. Within the context of language, Sliwa and Johansson (2015) enquired into the linguistic capital possessed by international staff in UK HE, where the performance of academic habitus, gaining acceptance and recognition in the UK academic field is influenced by language.

Miller (2016) concluded that that international academic staff may be seen as the 'others' would gain their acceptance in the UK academia through language. Miller (2016) coined the term 'white sanction', whereby the skills and abilities of international academics are initially acknowledged before being promoted by a white individual, who is often positioned as mediator.

Amidst current research, the extant literature does not delve in detail into the role of international academic staff in shaping institutional policies and practices related to internationalising UK HE, beyond the obvious. Consequently, there is much potential for UK HE to learn from the rich cultural and educational resources that international academics might offer to the wider academic community (Hsieh, 2012) and in shaping a more global, 
context-driven and internationalised curriculum (Larner, 2015). In a recent contribution, Willis and Hammond (2014) explore the contribution of international academic staff in the internationalisation of the academic community on campus and the shaping of a more internationally-informed curriculum. Amid these contributions, there has been a wider recognition of the importance of a deeper integration of the international academic community, discussed further in the next section.

\section{Calls for deeper integration of International academic staff in UK HE}

International academics in UK HE institutions are a rich source of cultural, pedagogic and academic experience; a theme that deserves further consideration, but that has not attracted much attention from academia to date (Bailey et al., 2016; Luxon and Peelo, 2009). An international perspective from Australia provided by Green and Myatt (2011), also suggests that despite the recognition of international academics as a resource to campus internationalisation, their value has not been fully recognised by institutions. Horta (2009) examined the French HE perspective, where the need for increased mobility and inclusion of international academic staff has been recognised as current challenge.

Institutional recognition, celebration and integration of the experience and expertise that international academic staff acquire across borders, may also play an important role in higher education curriculum innovation and internationalisation, as concluded by Hristov and Minocha (2017). However, Bailey et al. (2016) questioned whether the UK HE sector has fully enabled the integration of international academic staff into a new academic environment.

Further, a number of academic contributions concluded that a diverse academic community on campus can unlock curricular and pedagogic innovations (Bodycott et al., 2014; Green and Myatt, 2011; Kim, 2010). Academic staff, who have acquired experience across borders are considered as a source of informed global academic practice that brings about innovation in teaching and learning practice in the UK HE context (Hristov and Minocha, 2017). Amid these opportunities, no research has been conducted to unfold individual approaches and practices to curricular and pedagogic innovation.

International perspectives, alongside evidence from UK HE, strengthen current debates on the need for deeper integration of international academics, particularly in light of their international cultural, pedagogic and academic experience that may bring about innovation in teaching and learning (Green and Myatt, 2011; Hristov and Minocha, 2017; Kim, 2010. This provides opportunities for the introduction of enablers and resources that might be deployed to promote innovation and encourage greater cultural diversity and internationalisation in relation to curriculum and pedagogy.

Luxon and Peelo (2009) call for further enquiry, which is grounded in a wider understanding of diverse, culturally-fused pedagogic frameworks and how these shape teaching practices adopted by non-UK academic staff. In-depth studies are required, which cover diverse practices, techniques and approaches to delivering pedagogy and shaping curriculum adopted by the international academic community as part of their international academic experience and identifying pedagogies that may be effective in a UK HE context (Luxon and Peelo, 2009). Having provided evidence from the literature and HE practice on the importance of 
international academic staff integration, the final section of the review expands on the state of the international academic community in UK HE. This final literature review section sets the scene for the adopted methodology and the case study setting of this paper.

\section{International academic staff in $\mathrm{UK} \mathrm{HE}$}

The research evidence across the above-mentioned themes is in contrast to the increase of this academic cohort in UK HE, in recent years. The international academic community represent $29 \%$ of the overall number of UK full-time academic staff or a total of 58,280 academics (Universities UK, 2017) and is growing (see Figure 1). Consequently international academics are inevitably increasing in input and influence, as the longitudinal data on Figure 1 suggests.

[Figure 1. Full-time (non-UK) academic staff (Source: Universities UK, 2017)]

International staff entering the academic 'supply chain' in the UK do so in areas deemed to be of strategic importance to the economy, environment and society; in particular in subject areas such as science, technology, engineering and mathematics (STEM) (Hsieh, 2015; Larner, 2015; Universities UK, 2007). However, the sector has been paying little attention to the unique opportunities they may be bringing to UK HE in enriching internationalisation on our campuses (Clifford and Henderson, 2011).

The HEA calls for recognition of the opportunities that international and global perspectives bring to the UK HE sector in enriching the curriculum. This is a strong call, echoed in the HEA's recent Internationalisation Framework (HEA, 2014) and their data bank featuring a range of resources and approaches towards internationalising the curriculum (HEA, 2015).

On the basis of the themes identified in the literature, this paper aims to develop further understanding in relation to the experiences of international staff in UK HE. The rationale behind the research is grounded in the opportunity to recognise the wider role that international academic staff play in enabling UK HE become truly internationalised.

There have been a few attempts to define and deconstruct the profile of international academics internationally and in UK HE (see Jankovska and Kukhareva, 2014; Quddus et al., 2008). However for the purpose of this paper, international academic staff are individuals who have relocated from their home country to take up either teaching or research roles in the UK, who have been introduced to UK HE teaching and learning practice and who have had at least six months experience of this context to enable them to share their reflections and experience.

\section{Methods}

A review of research related to international academic staff in UK HE, enabled the identification of prominent themes, which have been insufficiently addressed by academic research. This provided shape to the adopted methodology. 
Data was collected over a period of four months - March to June 2015 - and comprised a sample of 34 international academic staff from over 15 countries (11\% of the international academic community within the UK HE institution chosen for this research). Although staff were drawn from the UK HE institution chosen for this research, the insights and experiences they refer to, are grounded in their wider international experience across HE institutions, both internationally and in the UK.

Two focus groups with a diverse cohort of international academic staff took place in May 2015. This was then supplemented by themed in-depth interviews with ten staff representing the international academic community (Table 1).

[Table 1. Research sample]

A total of 215 academic staff identified themselves as being 'international' with a non-UK country of origin based on HR records. They were invited to attend one of two focus groups. Focus groups were seen as an opportunity for international academic staff to voice their perspectives on prominent themes identified by the background review of the literature. The data collected was entirely qualitative and all comments captured were treated as anonymous.

In addition to the two focus groups, themed in-depth interviews with international academic staff, who had not attended one of the focus groups, were undertaken. The purpose of this activity was twofold: to facilitate deeper and more personalised engagement with individuals representing the studied international academic body; and to unpack the themes and issues that emerged from the focus group sessions.

Focus group discussion and subsequent interviews, addressed the four broad themes, drawn from the literature, namely:

- The UK HE context, including UK HE policy and practice through the perspective of international academic staff;

- The PG Cert: Perspectives and experiences of international academic staff;

- Innovative pedagogic practice as practiced by international academic staff across borders;

- The enablers of embedding greater diversity, internationalisation and culturallyinclusive curriculum.

Data were transcribed and analysed around the themes. The next section provides a discussion of prominent findings structured around the four themes.

\section{Study findings}

\section{The UK HE context through the perspective of international academic staff}

As discussed in the outset, the first objective of this paper was to unfold key dimensions of the UK HE context and related characteristics through the lens of international academic staff. These context dimensions are not definitive, or comprehensive as they reflect individual 
accounts of participants in this study but important nevertheless. The findings point to a multitude of challenges and opportunities faced by international academic staff upon their arrival in the UK, namely current policy and practice surrounding international academic staff inductions, the experience of international academic staff of UK HE processes and practices, and the relationship between educator and learner.

\section{Current policy and practice surrounding international academic staff inductions}

Building support structures are among the key characteristics of institutional policy and practice surrounding international academic staff and indeed a characteristic of the UK HE context. Support structures for staff may well be seen as the building blocks of an enabling environment for international academic staff, particularly throughout induction and the early stages of their career journey in foreign institutions.

Building on Jiang et al. (2010) and Maunder et al. (2009) investigations into the support for academic staff and their introduction to a new policy and practice context, participants voiced their perspectives on integration into UK HE. Among the most consistently voiced testaments were to do with current institutional policies and practices concerning international academic staff inductions in UK HE, and the related challenges linked to their transition into a new academic context. Whilst there was a consensus that staff often had good working relationships with their colleagues, participants felt that there could be much better support to help staff adjust to teaching in the UK. Recalling their own early days, staff pointed to the perceived challenges in finding support at the early stages of their career within UK HE:
"It's difficult. You have to learn to be independent. I had a supportive colleague, who mentored me ... social life and work life in the UK are separate from each other. It's often the case that international staff are not often invited to opportunities to socialise"

(Focus group participant)

Additional support, as put forward by one participant, could be in the form of an enhanced, more internationally focused, induction. It was also suggested that it would be beneficial to provide more networking opportunities and better support for staff around key issues such as student feedback and adapting to contrasting HE contexts:

\section{"I feel that there is generally a lack of welcoming for international staff. The inductions are not particularly internationally-focused ... I can see that this is changing, but at slow pace."}

(Focus group participant)

As a good practice in bridging the gap between UK HE expectations and the ability of international academics to become established within a new HE context, participants highlighted academic practice from Singapore where, "as a new staff member, you would normally work alongside expert lecturers in the first few terms." Participants therefore wanted to see more of this practice when international academic staff are introduced to UK HE. Staff suggested that they relied heavily on their networks of academics in their own institutions as a source of on-going support. They felt that one-off induction events may be failing to sufficiently address the multitude of challenges that they often faced as part of their 
relocation and acculturation. As such, they proposed that an on-going and more consistent approach to staff support was more likely to help with their transition:

"There is a lot of expectation placed on international staff in the first couple of weeks. There needs to be better integration. The institution needs to put more time and care into integrating international staff."

(Interview participant)

Staff also emphasised the importance of available support on matters beyond their academic life. One participant suggested that, "even simple things, such as settling-in, shopping and opening a bank account may prove problematic," and that staff would like to have more support with this. Staff also felt that any support put in place should extend beyond the confines of academia:

"It would be useful if international staff had a more comprehensive induction package and better support in getting set up in the UK ... it would be good if you have someone to signpost you. Good support from other staff is important in this sense."

(Interview participant)

Providing on-going support, and mentoring from fellow colleagues as well as enhanced communication concerning issues that international academic staff face at the beginning of their academic careers in UK HE, were seen as an important supplement to the more traditional inductions.

\section{The experience of international academic staff of UK HE processes and practices}

Luxon and Peelo (2009) discussed key challenges that international staff face in adapting to the UK HE context, as such challenges are often related to differences in academic processes and practices across countries. Staff in the focus groups and interviews, emphasised a range of differences in relation to their experience within UK HE when compared to their experience overseas, as part of previous academic roles.

When discussing programme structure, participants emphasised that generally, students in UK institutions tend to specialise early on in their programmes. Staff stressed that early course specialisation has not, however, been a common practice in countries such as India, Singapore and France, where courses had a broader, more generic content at the beginning with the aim to equip graduates with a degree that would enable them to find employment in their chosen field of study.

Staff also stressed that such practices adopted by HE systems in India, Singapore and France presented students with the opportunity to take a number of electives and specialise within a preferred discipline. Staff, therefore, saw this practice as providing students the opportunity to gain a broader, more cross-disciplinary education. This is a practice, which is not commonly adopted within the UK HE context.

Staff also pointed out a number of differences in the way curriculum was shaped and delivered in other countries, for example, curriculum in India was designed centrally to create a national standard and to ensure consistent quality throughout the sector. Participants, 
however, pointed out that "there is a certain degree of flexibility when assessing it [the curriculum]." In such cases, they felt academic staff had little control over the design of the curriculum, but did have flexibility over its delivery, and therefore a degree of freedom to decide on practiced pedagogies.

When drawing on their experience of assessment within HE, a participant commented that related approaches within UK HE are not particularly inclusive of diverse cultures and contexts:

"The way we assess and teach in the UK is very closed-off culturally, for example, we often ask UK-centric questions of our students in assessments. The UK HE context needs to take account of global considerations and this provision should be consistent across all institutional programmes."

(Interview participant)

Others felt that within the UK HE context, "there is no human touch but rather a tick-box approach," which may well be a result of the more independent approach to learning that is a key characteristic of UK HE.

Staff also felt that that they had not been particularly involved in important academic processes, such as the development of curriculum content and structure during their time in UK HE. They felt that their academic experience and expertise acquired across borders may well support institutional efforts towards internationalisation:

"There are opportunities to innovate and input into the curriculum and I think that international staff can and should be involved in this. This is an opportunity to innovate our programmes."

(Interview participant)

Further, some staff also believed that, when comparison was made to their previous experience overseas, "Things are much more bureaucratic in the UK; it 'beats' the educating out of education". As one participant shared, "the constant upgrade of curriculum, validation and revalidation, and involvement in work related to conformance to BCS [The Chartered Institute for IT], QAA [Quality Assurance Agency] and other accreditation agencies, distracts staff from designing and delivering a solid course."

\section{The relationship between educator and learner}

The relationship between international academic staff and students can often be problematic according to Hsieh (2012), who studied interactions between students and Chinese academics in UK universities. Another layer to this relationship was introduced by Schutte and Winkvist-Noble (2006), whereby international staff teach international students, which introduces further complexity to the UK HE teaching and learning environment. Within this context, the relationship between staff and students is another theme that emerged through conversations with international academics as part of this study. In general, the role between student and lecturer in the UK was described as being different to other countries. In the UK, 
staff believed students had more of a consumerist attitude and as such, their expectations and sense of power to appeal against assessments of their work seemed greater:

"International staff need to understand that the high fees have raised and changed the expectations of students ... the high fees reinforce the consumerist views of students in the UK."

(Focus group participant)

Another participant, who felt that these high expectations of students were particularly affecting international academic staff, voiced a similar opinion:

"I feel that many more students in UK HE are disrespectful and rude. Some are lovely, but they are in the minority. Some have real attitude problems. It takes time for students to open-up and relax with me. I think that the fact that I am international affects that relationship."

(Interview participant)

Within the context of the changing nature of the relationship between educators and learners, the introduction of a more 'student centred' approach to teaching and learning in UK HE (Hayes, 2017) through expressions, such as the Teaching Excellence Framework (TEF) (see HEFCE, 2017), may well be seen as a factor that shifts the balance of power from lecturers to students.

Further, it was suggested that the requirement for lecturers to provide frequent feedback to students in the UK was a contributory factor in exacerbating this sense of consumerism, as were the higher tuition fees. Some focus group participants, however, expressed the standpoint that UK HE pedagogies place an emphasis on more independent learning, which has not been the case when it comes to their academic experience in other countries. With the relationship between student and educator in mind, staff commented on the learning process in UK HE as being, "very much self-taught, whilst it provides some guidance from academics." One may well then argue that a demanding student culture and an independent learning culture could present contradictory perceptions from an international perspective.

\section{The PG Cert: Perspectives and experiences of international academic staff}

Building on the above discussion of findings on the UK HE context through the perspective of international academic staff, the second objective of this paper sought to provide a discussion of some perceptions that international academic staff hold in relation to the Postgraduate Certificate in Teaching and Learning (or equivalent), referred to in this paper as the PG Cert and their experiences. PG Cert and equivalents provide the foundational knowledge for academic staff involved in teaching and learning (Kandlbinder and Paseta, 2009). The perceived challenges and opportunities of undertaking the PG Cert were raised by a number of participants and focused on the content and structure of the PG Cert and to what extend it supported diverse pedagogic approaches. 
Staff felt that the PG Cert, in its present form, was too conventional and was underpinned by a very traditional, UK-centric perspective. This standpoint was shared on a number of occasions:

“Why doesn't the PG Cert focus on sharing practice rather than promoting a prescriptive doctrine? It feels like a demotion when you have previously lectured. The course can demotivate staff and as such, the PG Cert at present is not quite how we encourage our students to learn."

(Interview participant)

Another participant shared this view, where they drew a parallel with their overseas experience in order to compare and contrast it with the current UK HE PG Cert policy and practice:

"General feedback from me and my fellow staff is that it [the PG Cert] isn't of much use. It is too generic ... It should be flexible to accommodate and adjust to a multitude of disciplines."

(Interview participant)

Staff felt that recognising and embedding alternative approaches adopted overseas may well be considered as a means of improving current policy and practice around the PG Cert: "peer observation is a good practice from Singapore." In addition staff believed that "the PG Cert should be transformed into an internal teaching and learning conference" in order to capture and disseminate good practice.

Green and Myatt's (2011) developed five phases of transition for new international academic staff: preparing, arriving, re-establishing, reflecting and generating. Yet, as Green and Myatt (2011) suggest, what institutions overlook is the opportunity for reflective discussion, which is crucial for academic development and recognition of diverse pedagogic perspectives.

Interviewed staff questioned the extent to which the UK HE context embraces and recognises international practice within the context of shaping curriculum and encouraging innovative approaches to pedagogy. Whilst a number of staff thought that the PG Cert course was a useful mechanism for helping international staff prepare for teaching in the UK, it was felt that the course focused more on homogenising staff rather than embracing diverse pedagogic practices. They believed that, "in its present format, the PG Cert does not embrace or support different pedagogic approaches." For example, one participant explained:

"The PG Cert at present is too prescriptive and not inclusive of international staff expertise. There should be a mechanism in place to actively engage with international staff and for international staff to have the opportunity to contribute ... there needs to be better fusing of processes by making better use of personal, human engagement."

(Interview participant)

Consistent with the first discussion sub-theme, participants also concluded that the PG Cert should consider opportunities for the dissemination of good practice and consequently there was a need for a platform where staff could share their personal experience and, learn about the diverse cultural practices of others. 


\section{Innovative pedagogic practice as practiced by staff across borders}

The third objective of this paper sought to highlight any pedagogic practices as practiced by international academic staff across borders, which may be considered as innovative. The growing international academic body in the UK presents considerable opportunities in transforming the content and delivery of programmes within UK HE (Minocha, 2016). International academic staff can, therefore, be considered to be a source of informed global practice (Larner, 2015). Triggering a discussion on pedagogic practice beyond the UK HE context may therefore enable pedagogic innovation by challenging tacit assumptions about 'western' approaches to pedagogy (Hristov and Minocha, 2017). Consequently, participants were invited to share good practice beyond the UK HE context and provide insight into a range of distinct approaches to the development and delivery of pedagogic and curricular interventions.

It should be acknowledged that very few specific examples were identified of where staff had used alternative approaches to teaching. This may be partly related to current policy and practice surrounding the PG Cert, as presented above. Within this context, others questioned the extent to which cross-border pedagogic practice can be translated into the UK HE context, due to existing processes of homogenising academic practice, again. As a general comment, some staff had noticed that in the UK, colleagues, either UK or other international colleagues, seemed more reluctant to introduce controversial or topical issues into their lectures, which they put down to fear of redress.

Some staff commented that they believed that internationalisation prompts innovation. They felt that it pushed institutions to think of shaping and embedding innovative approaches to delivering their programmes and opens up opportunities for recognition and adoption of the academic experience of international academic staff in UK HE.

Staff felt that whatever the innovation element considered and embedded in existing pedagogies, that element should in its broadest sense, "allow international academic staff to grow organically," and also, "provide students with opportunities to explore further afield." Staff identified a multitude of pedagogic practices drawing on their experience abroad. Some of these included problem-based teaching and project-based learning, using rich media in the classroom, embedding international case studies.

Problem-based teaching, which offers innovation through embedding practice elements in pedagogies (Duch et al., 2001), was identified as strength of UK HE, and participants commented that the introduction in lectures and seminars of problem-based examples and case studies promoted better levels of interaction and engagement amongst students. Staff, however, suggested that the use of project-based teaching can build upon the commonly adopted problem-based teaching, and could add an international dimension to the classroom.

One participant expanded on the benefits of global project-based learning, which was what they deemed good practice in the innovation of the more traditional, problem-based pedagogic approaches:

"Project-based teaching is something, which is more engaging and allows students to get something tangible at the end of their learning. You have the 
opportunity to draw on global perspectives across various disciplines ... I will give you an example, where I adopted a multimedia publishing platform for journalism students giving them the space for fusing theory and practice."

(Interview participant)

This finding was echoed in the focus group discussions where participants felt that projectbased learning, which also promoted collaborative learning (as in the case of journalism students), was key to embedding internationalisation and innovation into the existing curriculum.

Institutional efforts aimed at the recognition and adoption of good practice are closely associated with exploring the wider enablers of embedding greater diversity of academic policy and practice and shaping a culturally inclusive curriculum. Enablers, seen as important through the perspective of international academic staff, are discussed further below.

\section{Enablers of embedding greater diversity, internationalisation and culturally-inclusive curriculum}

The final objective of this paper sought to explore some key enablers of internationalised curriculum from the perspective of international academic staff. Embedding diversity in HE institutions and culturally-inclusive curriculum can assist with campus internationalisation (Caruana and Ploner, 2010) and the integration of academic staff into UK HE. Focus group participants felt that staff mobility can benefit institutional internationalisation efforts and strongly supported the statement that, "we should take students and staff abroad as an opportunity to internationalise." Other participants also believed that introducing wider mobility opportunities could contribute to greater campus internationalisation:

\footnotetext{
"We need to create opportunities to expose more staff to international experiences. By this, I mean both teaching and learning experiences. This needs to be done carefully and with purpose. It needs to be culturally sensitive."
}

(Interview participant)

Building on the above, some respondents emphasised the importance of enabling two-way opportunities for mobility as a proactive approach to the promotion of deeper internationalisation on campus by suggesting that "we should also bring in overseas lecturers from diverse institutions to infuse international expertise in the curriculum".

Others suggested that actions aimed at breaking down the existing barriers between home and international students was a fundamental step towards enabling internationalisation and promoting greater diversity on campus:

"We need to make sure that we are very clear about the balance between international and home students ... Most international students come here for the exposure. We need a strategy for exposure, including one that fuses international and home students' perspectives."

(Interview participant) 
Participants felt that regardless of the approach taken, first and foremost, "we need to be open, collaborative and treat international academic staff with respect." They also believed that encouraging interaction has the potential to provide the basis for greater diversity and a more culturally-inclusive curriculum not just among staff, but also across the student body:

"We need to do more about interactive learning processes. We need to encourage more collaborative learning among different students. My students were initially resistant, but this approach turned out to be successful."

(Focus group participant)

The above discussion then suggests that important activities, such as two-way mobility of staff and students, guest lectures by academic staff from overseas universities, along with breaking down existing barriers between home and international students are all seen as key enablers for greater cultural diversity and internationalisation.

\section{Discussion}

Staff identified the need for the introduction of support resources, which would help with their transition into the UK HE and also assist with their life in the UK beyond the classroom. Narrow approaches and one-off events, such as staff induction, although necessary, might not always be able to provide the level of support required by international academic staff, new to UK HE. Staff felt that they would benefit from additional continuous support, such as a buddy scheme, and supported the development of platforms to encourage on-going dialogue with the wider academic community. As Smith (2010) notes, in times when universities increasingly pursue internationalisation, the diverse range of cultural values and practices on campus, should be reflected in institutional policy and practice; international academic staff should be at the heart of institutional moves in this direction. This process should start with the very introduction of staff to the UK HE context.

Findings suggested that a reflection upon existing institutional approaches surrounding the PG Cert, or equivalent, might prove beneficial. This is particularly important in times when international academic staff contribute to $29 \%$ of UK HE's academic body (Universities UK, 2017). This is also important amid sectoral pressure for institutions to reshape their offering so that it is responsive, timely and relevant to the wider economic, political and societal context, in which graduates will be expected to contribute to. The discussions suggested that the PG Cert at present might be referred to as not being fully inclusive and accommodative of international staff expertise. Staff identified a need to establish a mechanism or process to secure active engagement with other international staff. This mechanism would enable staff to contribute to a global faculty and classroom by drawing on their diverse international academic experience.

These findings are in line with a research undertaken by the Equality Challenge Unit (2013) into international academic staff within UK HE, which suggested that $78.9 \%$ of those questioned felt that their international experience and background have the potential to enrich institutional teaching and learning practice. However, the Equality Challenge Unit (2013) also emphasised that opportunities for staff to use these aspects in practice, remain untapped. As a result, the UK HE sector may be losing out on the opportunity to introduce a more inclusive PG Cert, which has the potential to introduce pedagogic innovations. This may well 
be seen as a strategically important consideration, in times when internationalisation is at the very core of institutional policy and practice and the delivery of a globally-informed programme offering is considered a competitive advantage (De Haan, 2014; Universities UK International, 2017).

As already outlined, this research drew on $11 \%$ of the international academic community at the UK HE institution chosen for this research. This suggests that there is more good practice to be uncovered. Facilitating a discussion on pedagogic practice beyond the UK HE context, which starts as part of the PG Cert and continues throughout the academic career, may in turn enable pedagogic innovation, by challenging tacit assumptions about UK HE approaches to pedagogy. In line with this, Hsieh (2012) argued that universities in the UK should learn from and recognise the rich educational resources of international academics, rather than simply expecting them to fit within the current context.

While there is an opportunity to recognise international academic staff as a source of globally-informed academic practice with potential to catalyse innovation in teaching and learning, there are barriers and challenges to accommodating international academic practice within the UK HE context. Pedagogical approaches and cultural values acquired by academics outside of the UK HE context may not fully align with British values, both in academia and outside, and indeed, with the expectations of both international and British students.

Alongside the challenges and opportunities related to the PG Cert, staff proposed enablers of campus internationalisation and shaping a more culturally-inclusive curriculum, such as strengthening the relationship between home and international students and the introduction of a more collaborative and interactive approaches to learning. These enablers were seen to be adding to the classroom experience of both home and international students and the transition of international academics into the UK HE context. Viewing international academic staff themselves, as enablers of campus internationalisation, is consistent with a recent research undertaken by Willis and Hammond (2014), who argued that this academic cohort has the potential to enrich both the curriculum and educational experience of students and as such, it provides a range of internationalisation opportunities.

\section{Conclusion}

The purpose of this paper was to explore the role of international academic staff in UK HE, as a resource of internationally-informed and innovative pedagogic practice. The underpinned research intended to enhance the current understanding of some diverse approaches adopted across the globe, and the range of opportunities available to UK HE, to recognise and capitalise on these diverse approaches, as well as the invaluable role of international academics in campus internationalisation.

The literature review demonstrated that current empirical evidence on the approach to internationalisation adopted by international academic staff, their experience of engagement with the PG Cert or equivalent, and their experience of UK HE more widely, is very limited (Hsich, 2012; Hristov and Minocha, 2017). In addition, little evidence exists in terms of recognition of the diversity of approaches that international staff adopt as part of their academic experience across borders. Despite the proportion of full-time international 
academic staff in the UK HE sector currently standing at 29\% (Universities UK, 2017), this cohort is still largely an unexplored resource. Consequently, international academics in UK HE represent an untapped opportunity to inform the shaping of a curriculum that is globallyrelevant and innovative.

This is not to forget that UK HE staff, who are UK-born, alongside international academic staff also have responsibility for internationalisation on campus and the internationalisation efforts, initiatives and programmes of the former group can be enhanced and further enriched through the inclusion of international academic staff.

As the research summary shows, international academic staff can play an important role in the process of recognition and adoption of diverse methodologies as the basis of both curriculum innovation and campus internationalisation. International staff themselves called upon the introduction of more opportunities to allow them to contribute to a global faculty and classroom by drawing on their diverse academic experience across borders.

\section{Research limitations}

Whilst the staff focus groups were open to all international academic staff the sample of 34 represented $11 \%$ of the total number of this academic cohort $(n=215)$. Although the sample included representation from across all four Faculties of the case institution, the views may not be representative of the entire international academic community at this institution.

Building on this relatively small-scale study and the resultant sample, it is important to note that the emergent themes alongside each of the four objectives are neither definitive, nor comprehensive: they reflect individual accounts of participants in this study derived from a single HE institution in the UK. Thus, they are not generalisable, as they do not represent the totality of the international academic staff body in the UK

Further to that, a significant number of staff from the studied international academic community have only taught in the UK HE context. Hence the extent to which they are able to identify innovative pedagogic practice used globally may be limited. At last, this research has not fully captured sufficient international academics, who are new to the UK HE context and who are more likely to provide a richer and more lived account of HE policy and practice beyond the UK HE context.

\section{Avenues for further research}

The background review of recent academic contributions investigating the experience, role and contribution of international academic staff to the UK HE sector indicated that current evidence within this research domain is weak (see Hsich, 2012; Willis and Hammond, 2014). Further enquiry would likely therefore benefit both academia and practice, in the following areas:

- Identifying approaches to facilitating the transition of and the provision of ongoing support for international academics into the UK HE context;

- Exploring alterations to the PG Cert model as an induction to teaching and learning practices in UK HE, whilst embracing diversity and creativity; 
- Recognising good practice of international academic staff and identifying ways of adopting it within the UK HE;

- Conducting an in-depth investigation into the enablers of a more culturallyinclusive curriculum which is shaped in partnership with the international academic community.

Future studies should also consider the inclusion of a larger sample of international academic staff through a more strategic sampling approach with a focus on triangulation. A quantitative approach that enables the examination of individual accounts while targeting a larger staff response base, may enable the identification of other themes in relation to the integration and experience of international academic staff.

There is an opportunity for greater recognition of international academic staff and the role they can play in campus internationalisation processes within UK HE. Senior institutional leadership can play a key role in the introduction and provision of continuous support to university-wide efforts in this direction.

Specifically, international staff are a valuable resource in assisting the internationalisation of universities and this merits greater recognition. Top teams can explicitly realise this potential though working in partnership with their international staff. Mobilising resources to enable this partnership would be a pre-requisite.

International academics can provide a range of enrichment opportunities for UK HE. HE institutions should take further steps to capitalise on such internationally-informed campus internationalisation. Although this paper has proposed that the international academic community might play a wider role in ensuring that UK HE is truly international, the discussion and findings are relevant globally. HE in any cultural context needs to consider how diversity contributes to enhance curriculum and pedagogy in a context of globalisation. 


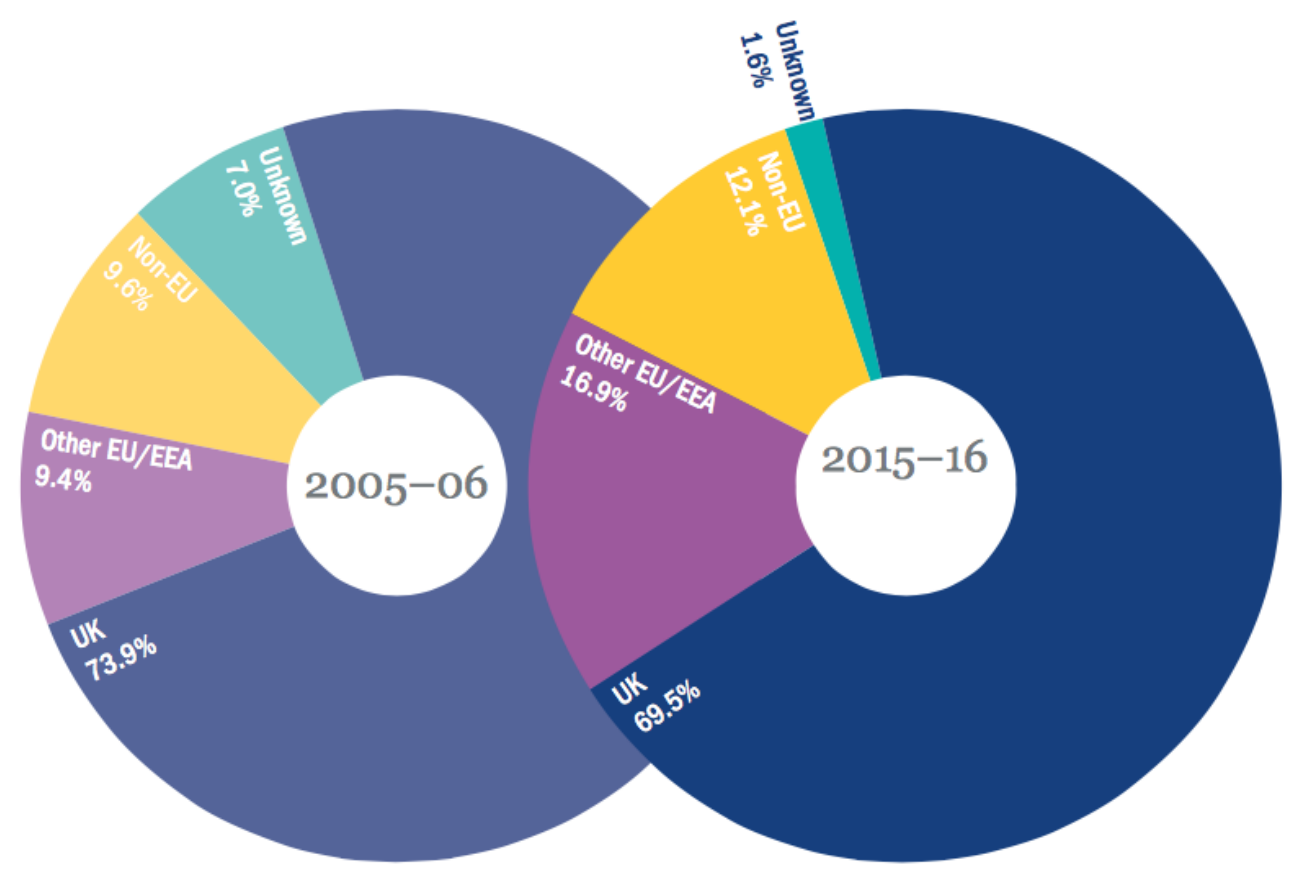

Figure 1. Full-time (non-UK) academic staff (Source: Larner, 2015) 
Table 1. Research sample

\begin{tabular}{|c|c|c|}
\hline & Invited & Attended \\
\hline Focus group 1 (International academic staff) & 215 & 15 \\
\hline Focus group 2 (International academic staff) & - & 9 \\
\hline Interviews (International academic staff) & 10 & 10 \\
\hline Total & 225 & 34 \\
\hline
\end{tabular}




\section{References}

Altbach, P. G., \& Knight, J. (2007). The internationalization of higher education: Motivations and realities. Journal of studies in international education, 11(3-4), 290-305.

Bailey, W., Bordogna, C., \& Harvey, H. (2016). Creating a veneer of internationalisation? Are UK higher education institutions doing enough to integrate international academic staff into their working environment?

Barrington, E. (2004). Teaching to student diversity in higher education: How multiple intelligence theory can help. Teaching in Higher Education, 9(4), 421-434.

Barend, S. \& Winkvist-Noble, L. (2006), Foreigners Teaching Foreigners: The Enhancement of International Students ' Experience from an International Point of View', 3rd Annual Conference, The International Learner: Enhancing the Student Experience September 13-14 2006. Southampton- Southampton Solent University, pp. 119-130.

Blight, D., Davis, D., \& Olsen, A. (1999). The internationalisation of higher education. Higher education through open and distance learning, 15-31.

Brandenburg, U., \& De Wit, H. (2015). The end of internationalization. International higher education, (62). Chicago.

Cai, L., \& Hall, C. (2016). Motivations, expectations, and experiences of expatriate academic staff on an international branch campus in China. Journal of Studies in International Education, 20(3), 207-222.

Caroll, J., \& Ryan, J. (2005). Eds. Teaching International students improving learning for all. Abingdon: Routledge.

Caruana, V., \& Ploner, J. (2010). Internationalisation and equality and diversity in higher education: merging identities.

Clifford, V. A., \& Henderson, J. (2011). Shifting identities: International staff negotiating new academic identities. Melbourne: Victoria University.

Crose, B. (2011). Internationalization of the Higher Education Classroom: Strategies to Facilitate Intercultural Learning and Academic Success. International Journal of Teaching and Learning in Higher Education, 23(3), 388-395.

De Haan, H. (2014). Can internationalisation really lead to institutional competitive advantage?-a study of 16 Dutch public higher education institutions. European Journal of Higher Education, 4(2), 135-152.

Duch, B. J., Groh, S. E., \& Allen, D. E. (2001). The power of problem-based learning: a practical" how to" for teaching undergraduate courses in any discipline. Stylus Publishing, LLC. 
Equality Challenge Unit (2013) Improving the Experiences of International Staff in UK Higher Education: Research Report. London: Equality Challenge Unit

Fernando, W. D. A., \& Cohen, L. (2015). Exploring career advantages of highly skilled migrants: a study of Indian academics in the UK. The International Journal of Human Resource Management, 1-22.

Green, W., \& Myatt, P. (2011). Telling tales: A narrative research study of the experiences of new international academic staff at an Australian university. International Journal for Academic Development, 16(1), 33-44.

Harrison, N. (2015). Practice, problems and power in 'internationalisation at home': critical reflections on recent research evidence. Teaching in Higher Education, 20(4), 412-430.

Hayes, D. (2017). Beyond the mcdonaldization of higher education. Beyond McDonaldization: Visions of Higher Education, 1.

HEA (2015) Internationalising the Curriculum. Available at:

https://www.heacademy.ac.uk/resources/detail/internationalisation/ISL_Internationalising_th e_curriculum (Accessed 26 May 2015).

HEA (2014a) Internationalising the Curriculum. London: The Higher Education Academy

HEA (2014b) Internationalising Higher Education Framework. Available at: https://www.heacademy.ac.uk/internationalising-higher-education-framework (Accessed 26 May 2015).

HEFCE (2017) About the TEF. Available at: http://www.hefce.ac.uk/lt/tef/whatistef/ (Accessed 24 October 2017).

Hristov, D. and Minocha, S. (2017) The role of the international academic community in shaping global campuses and classrooms. Universities UK International. Available at: http://www.universitiesuk.ac.uk/International/Pages/the-role-of-the-international-academiccommunity-in-shaping-global-campuses-and-classrooms.aspx (Accessed 22 October 2017)

Hsieh, H. H. (2012). Challenges facing Chinese academic staff in a UK university in terms of language, relationships and culture. Teaching in Higher Education, 17(4), 371-383.

Hudzik, J. K. (2015). Strategic Institutional Partnerships and Comprehensive Internationalisation. Higher Education: Partnerships for the Future. Porto Elizabeth: Unit for Higher Education Internationalisation in the Developing World, 23-39.

Jankovska, M. and Kukhareva, M. (2014) What does it mean to be a foreign academic entering a British university? Experiential exploration and implications for CPD practice. London: Society for Research into Higher Education. 
Jones, E. (2009). Shouldn't all faculties be international? The International Faculty at Leeds Metropolitan University. Enhancing Learning in the Social Sciences, 2(1), 1-19.

Jones, E. \& Brown, S. (eds.) (2007). Internationalising higher education. Abdingdon, UK: Routledge.

Kandlbinder, P., \& Peseta, T. (2009). Key concepts in postgraduate certificates in higher education teaching and learning in Australasia and the United Kingdom. International Journal for Academic Development, 14(1), 19-31.

Khattab, N., \& Fenton, S. (2015). Globalisation of researcher mobility within the UK Higher Education: explaining the presence of overseas academics in the UK academia.

Globalisation, Societies and Education, 1-15.

Kim, T. (2010). Transnational academic mobility, knowledge, and identity capital. Discourse: Studies in the Cultural Politics of Education, 31(5), 577-591.

Larner, W. (2015). Globalising knowledge networks: Universities, diaspora strategies, and academic intermediaries. Geoforum, 59, 197-205.

Jones, E. (2008). World-wide Horizons at Leeds Metropolitan University. In Atfield. R. and Kemp, P. (Eds). Enhancing the International Learning Experience in Business and Management, Hospitality, Leisure, Sport, Tourism. Newbury, Berks: Threshold Press.

Leask, B. (2009). Using formal and informal curricula to improve interactions between home and international students. Journal of Studies in International Education, 13(2), 205-221.

Leask, B. \& Carroll, J. (2011) Moving beyond 'wishing and hoping': internationalisation and student experiences of inclusion and engagement, Higher Education Research \& Development, 30:5, 647-659, DOI: 10.1080/07294360.2011.598454

Luxon, T., \& Peelo, M. (2009). Academic sojourners, teaching and internationalisation: The experience of non-UK staff in a British University. Teaching in Higher Education, 14(6), 649-659.

Marschan-Piekkari, R., \& Welch, C. (Eds.). (2011). Rethinking the case study in international business and management research. Edward Elgar Publishing. Chicago

Maunder, R., Di Napoli, R., Borg, M., Fry, H., Walsh, E., \& Jiang, X. (2009). Acculturation into UK academic practice: the experiences of international doctoral students and academic staff at two research-intensive universities. Northampton: The University of Northampton.

Mavroudi, E., \& Warren, A. (2013). Highly skilled migration and the negotiation of immigration policy: Non-EEA postgraduate students and academic staff at English universities. Geoforum, 44, 261-270.

McLoughlin, C., \& Lee, M. J. (2010). Personalised and self regulated learning in the Web 2.0 era: International exemplars of innovative pedagogy using social software. Australasian Journal of Educational Technology, 26(1). 
Miller, P. (2016). 'White sanction', institutional, group and individual interaction in the promotion and progression of black and minority ethnic academics and teachers in England. Power and Education, 8(3), 205-221.

Minocha, S. (2016) Shaping a Global BU: Internationally-informed Internationalisation. London: The Higher Education Academy. Available at: https://www.heacademy.ac.uk/resource/shaping-global-bu-internationally-informedinternationalisation (Accessed 10 October 2016)

Pherali, T. J. (2012). Academic Mobility, Language, and Cultural Capital The Experience of Transnational Academics in British Higher Education Institutions. Journal of Studies in International Education, 16(4), 313-333.

Pimpa, N. (2009). The meanings of'the internationalisation of the curriculum'in Australian higher education. International Journal of Innovation and Learning, 6(2), 217-233.

Quddus, M., Quazi, R., Debnath, S., \& Tandon, S. (2008) International Faculty In US Business Schools: A Descriptive Study.

Robson, S., \& Turner, Y. (2007). 'Teaching is a co-learning experience': academics reflecting on learning and teaching in an 'internationalized' faculty. Teaching in Higher Education, 12(1), 41-54.

Śliwa, M., \& Johansson, M. (2015). Playing in the academic field: Non-native Englishspeaking academics in UK business schools. Culture and Organization, 21(1), 78-95.

Smith, J. (2010). Academic identities for the twenty-first century. Teaching in Higher Education, 15(6), 721-727.

UNESCO (2015) Global Flow of tertiary-level Students. Available at: http://www.uis.unesco.org/Education/Pages/international-student-flow-viz.aspx (Accessed 29 August 2015)

Universities UK, (2007). Talent Wars: The International Market for Academic Staff, Policy Briefing. London: Universities UK.

Universities UK (2017) International higher education in facts and figures 2017. Available at: http://www.universitiesuk.ac.uk/policy-and-analysis/reports/Pages/international-facts-figures2017.aspx (Accessed 24 October 2017).

Universities UK International (2017) UK Strategy for Outward Student Mobility 2017-2020. London: Universities UK International.

Vita, G. D. (2001). Learning styles, culture and inclusive instruction in the multicultural classroom: A business and management perspective. Innovations in Education and Teaching International, 38(2), 165-174.

Walker, P. (2015). The globalisation of higher education and the sojourner academic: Insights into challenges experienced by newly appointed international academic staff in a UK university. Journal of Research in International Education, 14(1), 61-74. 
Wamboye, E., Adekola, A., \& Sergi, B. S. (2015). Internationalisation of the campus and curriculum: Evidence from the US institutions of higher learning. Journal of Higher Education Policy and Management, 37(4), 385-399.

Warwick, P. (2008). Listening to International Students. In Enhancing the international learning experience in business and management hospitality leisure sport tourism. Atfield, R. \& Kemp, P. Newbury: Threshold Press.

Willis, J. and Hammond, A. (2014). An investigation of the contribution made by international staff to internationalisation of learning and teaching practices within tertiary education in the UK. London: The Higher Education Academy 